\title{
EPIDEMIOLOGY OF CONGENITAL MALFORMATIONS IN KAZAKHSTAN
}

\section{Altynay SADYKOVA ${ }^{1}$, Riza BORANBAYEVA ${ }^{1}$, Gulbanu BERDIYAROVA ${ }^{1}$, Karligash ZHUBANYSHEVA ${ }^{2}$, Svetlana ANOHINA ${ }^{1}$, Mukhtar KULIMBET ${ }^{3,4}$, Dinara OSPANOVA ${ }^{3}$, Shynar TANABAYEVA ${ }^{4}$, IIdar FAKHRADIYEV ${ }^{4} \bowtie$}

${ }^{1}$ Scientific Center of Pediatrics and Pediatric surgery, Almaty, Republic of Kazakhstan

${ }^{2}$ The Kazakhstan's Medical University “Kazakhstan School of Public Health”, Almaty, Republic of Kazakhstan ${ }^{3}$ Al-Farabi Kazakh National University, Almaty, Republic of Kazakhstan

${ }^{4}$ S.D. Asfendiyarov Kazakh National Medical University, Almaty, Republic of Kazakhstan

Received 06 May 2021, Accepted 11 July 2021

https://doi.org/10.31688/ABMU.2021.56.3.03

\section{Abstract}

Introduction. Congenital malformations are the main cause of morbidity and mortality amongst newborns. The detailed epidemiological data about congenital anomalies in Kazakhstan have not been reported yet.

The objective of the study was to estimate the prevalence of congenital malformations and their regional distribution in Kazakhstan. In addition, the study aimed to assess the cause-specific death rate, perinatal, neonatal, post-neonatal, and infant mortality rates for the period 2015-2019.

Material and methods. The descriptive cross-sectional study was based on data obtained from the Republican Centre of Health Development (18 regions of Kazakhstan) for the period 2015-2019.

Results. In 2019, the prevalence of total congenital malformations decreased by $30-40 \%$ compared to 2015. At the same time, the prevalence of congenital malformations of the respiratory system increased by $14 \%$. The congenital cardiovascular malformations prevailed (18.3 per 10,000 live births) in 2015 . The

\section{Résumé}

Epidémiologie des malformations congénitales en Kazakhstan

Introduction. Les malformations congénitales sont la principale cause de morbidité et de mortalité chez les nouveau-nés. Les données épidémiologiques détaillées sur les anomalies congénitales au Kazakhstan n'ont pas encore été rapportées.

L'objectif de l'étude était d'estimer la prévalence des malformations congénitales et leur répartition régionale au Kazakhstan. En outre, l'étude visait à évaluer le taux de mortalité par cause, les taux de mortalité périnatale, néonatale, post-néonatale et infantile pour la période 2015-2019.

Matériel et méthodes. L'étude transversale descriptive était basée sur des données obtenues du Centre républicain pour le développement de la santé (18 régions du Kazakhstan) au cours de la période 2015-2019. Résultats. En 2019, la prévalence des malformations congénitales totales a diminué de 30 à $40 \%$ par rapport à 2015. Dans le même temps, la prévalence des 
highest values of mortality from congenital malformations were observed in South Kazakhstan. In 2019, the rates of perinatal (13.14), post-neonatal (3.89), neonatal (4.32), and infant mortality (8.21) per 1,000 live births showed a slight decrease. In 2019, an increase of perinatal mortality was observed compared to 2015 (from 13.96 to 14.29 per 1,000 live births), while neonatal mortality decreased from 8.33 to 6.08 per 1,000 live births, as well as infant mortality (from 11.33 to 9.42 per 1,000 live births).

Conclusions. During the 5-year period of the study, the analysis showed a decrease in the prevalence of some congenital malformations, such as malformations of digestive, urinary, nervous systems, and others. In the southern region of Kazakhstan there was a high rate of different forms of congenital defects, in particular, the circulatory system abnormalities. The results can be useful for the optimization of the national strategy, to reduce the prevalence of congenital malformations.

Keywords: congenital malformations, epidemiology, prevalence, Kazakhstan.

\section{List of abbreviations}

$\mathrm{CDC}=$ Centers for Disease Control and Prevention EUROCAT $=$ European Surveillance of Congenital Anomalies

WHO= World Health Organization

TOPFA $=$ Termination of pregnancy for foetal abnormality

UNICEF $=$ United Nations International Children's Emergency Fund

\section{INTRODUCTION}

Protection of maternal and child health, the increase of birth rate, and reduction of infant mortality are main priorities of many healthcare systems ${ }^{1}$. According to available data, the global prevalence of congenital malformations in 2012 was about 2-3\% ${ }^{2}$. Congenital malformations in developed countries are still one of the leading causes of infant morbidity and mortality ${ }^{1,3-5}$. As reported by the World Health Organization (WHO), 295,000 children die annually from malformations, within 28 days of life ${ }^{6}$.

According to the report of Centers for Disease Control and Prevention (CDC), in 2018, the deaths from congenital anomalies took the first place in the etiology structure of infant mortality, accounting for 118 cases per 100,000 live births ${ }^{3}$. As reported by European Surveillance of Congenital Anomalies (EUROCAT), about $2.5 \%$ of infants are born annually with various congenital defects. The total incidence malformations congénitales de l'appareil respiratoire a augmenté jusqu'à par 14\%. Les malformations cardiovasculaires congénitales prévalaient $(18,3$ pour 10 000 naissances vivantes) en 2015. Les valeurs les plus élevées de mortalité par malformations congénitales ont été observées dans le sud du Kazakhstan. En 2019, les taux de mortalité périnatale $(13,14)$, post-néonatale $(3,89)$, néonatale $(4,32)$ et infantile $(8,21)$ pour 1,000 naissances vivantes ont légèrement diminué. En 2019, une augmentation de la mortalité périnatale a été observée par rapport à 2015 (de 13,96 à 14,29 pour 1,000 naissances vivantes), tandis que la mortalité néonatale a diminué de 8,33 à 6,08 pour 1,000 naissances vivantes, ainsi que la mortalité infantile (de 11,33 à 9,42 pour 1,000 naissances vivantes).

Conclusion. Au cours de la période de 5 ans de l'étude, l'analyse a montré une diminution de la prévalence de certaines formes de malformations congénitales telles que les malformations des systèmes digestif, urinaire, nerveux et autres. Dans la région sud du Kazakhstan, il y avait un taux élevé de différentes formes de malformations congénitales, en particulier des anomalies du système circulatoire. Les résultats peuvent être utiles pour l'optimisation de la stratégie nationale visant à réduire la prévalence des malformations congénitales.

Mots-clés: malformations congénitales, épidémiologie, prévalence, Kazakhstan.

of congenital malformations varies widely, from 10.3 to 32.3 per 1,000 newborns $s^{4,7}$. Congenital malformations ranked second in the structure of causes of infant mortality in Kazakhstan ${ }^{8}$.

In fact, the congenital defect is a frequent cause of lifelong disability or mortality among children, requiring a long and expensive treatment and rehabilitation. In this regard, the analysis of epidemiological data and risk factors for congenital malformations can be helpful in preventing further spread of congenital malformations. Such an analysis can help to develop a complex of preventive official measures to reduce the rate of infant morbidity and mortality ${ }^{9-12}$.

The WHO classified congenital malformations as the group of eco-associated diseases that can serve as indicators for monitoring the quality of the environment. The analysis of information about the increase in the frequency and severity of congenital malformations facilitates the understanding of the ecological situation in each region. Hence, it is highly 
critical to collect and analyse data on the prevalence of congenital malformations ${ }^{6}$.

WHO resolution on birth defects $\left(63^{\text {rd }}\right.$ World Health Assembly, 2010, agenda item 11.7) has urged all countries to develop a population surveillance programme to accurately record congenital anomalies, to better understand the impact of this type of pathology. Up to date, significant efforts were taken in various countries in Europe and the United States of America to obtain information on the prevalence of congenital anomalies, to form a system of epidemiological surveillance and preventive measures ${ }^{12}$.

To date, in Kazakhstan there is no national surveillance programme for the registration of congenital anomalies. However, the statistical data of annual registration of congenital malformations are being recorded and presented in the statistical compendium "The Health of the population of the Republic of Kazakhstan and the activities of healthcare organizations" (published by the Ministry of Health of the Republic of Kazakhstan) ${ }^{8}$.

Kazakhstan is a country located in Eurasia, ranking $9^{\text {th }}$ in the world territory, with a population of $18,809,210$ people $^{13}$. Congenital malformations are the main cause of infant mortality in the Republic of Kazakhstan $^{8}$. Unfortunately, data on the prevalence and forms of congenital anomalies and territorial distribution in Kazakhstan are absent. There is little information available from statistical reports and sample population studies (depending on the location). A systematic review of literature sources over the past 10 years in the Republic of Kazakhstan showed that information on this topic remains vague. There are no published data on the epidemiology of congenital malformations in the Republic of Kazakhstan.

THE OBJECTIVE OF THE STUDY was to assess the epidemiology of congenital malformations and to analyse its regional distribution across Kazakhstan (for the period 2015 - 2019).

\section{Materials AND Methods}

\section{Study design}

This is a descriptive cross-sectional study of congenital malformations in Kazakhstan for the period 2015-2019, from the official statistical sources of the Republican Centre of Health Development (www. rcrz.kz).

\section{Ethical issues}

The study was approved by the Ethics Committee of the Kazakh Medical University of Continuing Education, Almaty, Kazakhstan (Local Ethics Commission Protocol No. 2 dated December 13, 2018).

\section{Data collection}

We retrospectively analysed the cases of congenital malformations in Kazakhstan for the period 2015-2019. The data were obtained from the annual statistical compendium "Health of the population of the Republic of Kazakhstan and the activities of healthcare organizations" for all regions of Kazakhstan from 2015 to $2019^{8}$. The following indicators were analysed (comparison between regions and cities of Kazakhstan): the total annual number of alive newborns with a certain type of congenital malformations, the total annual number of newborns who died with a certain type of congenital malformations, the total number of infant deaths (from birth to one year), and the causes of infant death (from birth to one year) $)^{8}$.

The study included all malformations newly diagnosed in the neonatal period and during the first year of life according to the WHO definition (2016). Congenital malformations are structural or functional abnormalities that appear during intrauterine development and can be detected before birth, during birth or later in life and that were registered in accordance with the International Classification of Diseases of the $10^{\text {th }}$ revision into the XVII class "Congenital anomalies (malformations), deformities and chromosomal abnormalities" (Q00-Q99): Q00-Q07 (Congenital malformations of the nervous system), Q10-Q18 (Congenital malformations of the eye, ear, face and neck), Q20-Q28 (Congenital malformations of the circulatory system), Q30-Q34 (Congenital malformations of the respiratory system), Q35-Q37 (Cleft lip and palate [cleft lip and cleft palate]), Q38-Q45 (Other congenital malformations of the digestive system), Q50-Q56 (Congenital malformations of the genital organs), Q60-Q64 (Congenital malformations of the urinary system), Q65-Q 79 (Congenital anomalies and deformities of the musculoskeletal system), Q80-Q89 (Other congenital anomalies), Q90-Q99 (Chromosomal disorders, not elsewhere classified $)^{14}$.

This study included infants who were diagnosed with "Congenital anomalies" at 25 to 41 weeks of pregnancy, weighing 500 grams or more, and who had a permanent residence in the Republic of Kazakhstan. The prevalence of congenital malformations was calculated per 10,000 live births. The cause-specific death rates were calculated per 100,000 live births.

Perinatal, neonatal, post-neonatal and infant mortality rates were calculated per 1,000 live births. Demographic characteristics (fertility, infant mortality) were collected and analysed, from data of the Committee of Statistics of the Ministry of National Economy of the Republic of Kazakhstan ${ }^{13}$. 
The inclusion criteria: all confirmed cases of congenital malformations. The exclusion criteria: cases of enzymatic and immune insufficiency.

\section{Statistical analysis}

All statistical calculations were conducted using SPSS software (version 22.0, IBM SPSS Inc., Chicago, Illinois, USA). We used demographic information obtained from the Statistics Committee of the Ministry of National Economy of the Republic of Kazakhstan on total population of the country, fertility rate and infant mortality ${ }^{13}$. The EUROCAT method was used for the prevalence (live birth) and mortality calculations.

The livebirth prevalence was calculated as the livebirths cases of congenital malformations in the population divided by the number of all live births in the population, as described in official birth registrations.

Cause-specific death rate was calculated and interpreted as the number of deaths from a specific type of congenital malformations divided by per 100,000person-years at risk for the specified time period.

Infant mortality rate was calculated as the number of resident newborns in a specified geographic area dying under one year of age divided by the number of resident live births for the same geographic area (for a specified time period, usually a calendar year) and multiplied by 1,000 .

Perinatal mortality rate was calculated from the sum of foetal deaths of 28 or more weeks gestation and the number of resident newborns dying under 7 days of age in a specified geographic area. After this, the number is divided by the sum of resident live births and the number of resident foetal deaths of 28 or more weeks of gestation for the same geographic area (for a specified time period, usually a calendar year), and then multiplied by 1,000.

Neonatal mortality rate is calculated as the number of resident newborns in a specified geographic area dying at less than 28 days of age divided by the number of resident live births for the same geographic area (for a specified time period, usually a calendar year) and multiplied by 1,000 .

Post-neonatal mortality rate is calculated as the number of resident newborns dying between 28 and 364 days of age in a specified geographic area divided by the number of resident live births for the same geographic area (for a specified time period, usually a calendar year), and then, multiplied by 1000 .

\section{Results}

For the period 2015-2019, 7,904 children with various types of congenital malformations were born in Kazakhstan $(0.4 \%$ of the total number of newborns) (Table 1).

The analysis indicated that the congenital malformations of the circulatory system prevailed (in $2015)$, i.e. 18.3 per $10,000(n=731)$. In the following years (2016-2019), the prevalence of circulatory system defects slightly decreased. However, the rate remained high among all congenital malformations.

In 2016 and 2017, the prevalence of congenital malformations of the circulatory system was almost the same: 16.3 and 16.0 per 10,000 live births.

The prevalence of congenital malformations of the musculoskeletal system and digestive organs in 2015 were about the same: 6.1 per $10,000(n=245)$ and 5.3 per $10,000(n=213)$. In 2016, the prevalence of congenital malformations of the musculoskeletal system and digestive system decreased to 5.3 per $10,000(n=212)$ and 4.1 per 10,000 ( $\mathrm{n}=165)$, respectively. Furthermore, after a slight increase in the prevalence of congenital malformations of the musculoskeletal system (6.0 per $10,000)$ and of the digestive system $(4.3$ per 10,000$)$ in 2017, these indicators showed a moderate decline to 4.3 and 3.1 per 10,000 births in 2019. The prevalence of congenital anomalies of the respiratory system in 2019 increased: 0.8 per 10,000 live births, in comparison with 2015 (0.7 per 10,000 births).

We have also established cause-specific death rates from congenital malformations in Kazakhstan (Table 2), which were calculated per 100,000 inhabitants (person-years at risk).

During the 5-year period covered by the study, there was a decrease of cause-specific death rate from congenital malformations. The cause-specific death rates from congenital malformations of the respiratory system decreased from 3.75 per 100,000 to 1.99 per 100,000 total population, from 2015 to 2019. In addition, during 2019, the cause-specific death rates from congenital malformations of the digestive tract decreased to 0.25 per 100,000 total population compared to 1.75 per 100,000 total population in 2015.

Furthermore, we also calculated and analysed the percentage change in the prevalence of various congenital malformations between 2015 and 2019 (Table 3). The prevalence of chromosomal abnormalities in 2019 decreased by $48 \%$, from 2.3 per 10,000 infants in 2015 to 1.2 per 10,000 infants in 2019. In addition, the prevalence of congenital defects of the digestive tract and anomalies of the urinary system in 2019 decreased by 42\% (compared to 2015). Besides, the prevalence of other congenital malformations in 2015 was found as 2.3 per 10,000 infants and greatly 
Table 1. Prevalence of congenital malformations in Kazakhstan per 10,000 births (2015-2019).

\begin{tabular}{|c|c|c|c|c|c|}
\hline \multirow{3}{*}{$\begin{array}{l}\text { Type of congenital malformation ac- } \\
\text { cording to ICD } 10\end{array}$} & \multicolumn{5}{|c|}{ Years } \\
\hline & $\begin{array}{c}2015 \\
n(\%)\end{array}$ & $\begin{array}{c}2016 \\
n(\%)\end{array}$ & $\begin{array}{c}2017 \\
n(\%)\end{array}$ & $\begin{array}{c}2018 \\
n(\%)\end{array}$ & $\begin{array}{c}2019 \\
n(\%)\end{array}$ \\
\hline & $p$ & p & $p$ & $p$ & $p$ \\
\hline $\begin{array}{c}\text { Congenital malformations } \\
\text { of the nervous system (Q00-Q07) }\end{array}$ & $98(0.025) 2.5$ & $77(0.019) 1.9$ & $83(0.021) 2.1$ & $78(0.020) 2.0$ & $\begin{array}{c}62(0.015) \\
1.5\end{array}$ \\
\hline $\begin{array}{c}\text { Congenital malformations } \\
\text { of the eye, ear, face and neck } \\
\text { (Q10-Q18) }\end{array}$ & $33(0.008) 0.8$ & $\begin{array}{l}48(0.012) \\
1.2\end{array}$ & $37(0.009) 0.9$ & $43(0.011) 1.1$ & $\begin{array}{l}27(0.0070) \\
0.7\end{array}$ \\
\hline $\begin{array}{c}\text { Congenital malformations } \\
\text { of the circulatory system (Q20-Q28) }\end{array}$ & $731(0.183) 18.3$ & $\begin{array}{c}655(0.163) \\
16.3 \\
\end{array}$ & $\begin{array}{c}628(0.160) \\
16.0 \\
\end{array}$ & $\begin{array}{c}526(0.132) \\
13.2 \\
\end{array}$ & $\begin{array}{c}464(0.116) \\
11.6 \\
\end{array}$ \\
\hline $\begin{array}{l}\text { Congenital malformations } \\
\text { of the respiratory system (Q30-Q34) }\end{array}$ & $28(0.007) 0.7$ & $22(0.0050) 0.5$ & $39(0.010) 1.0$ & $39(0.010) 1.0$ & $34(0.008) 0.8$ \\
\hline $\begin{array}{l}\text { Cleft lip and palate } \\
\text { [cleft lip and cleft palate] (Q35-Q37) }\end{array}$ & $134(0.034) 3.4$ & $127(0.032) 3.2$ & $150(0.038) 3.8$ & $122(0.031) 3.1$ & $85(0.021) 2.1$ \\
\hline $\begin{array}{l}\text { Other congenital malformations } \\
\text { of the digestive system (Q38-Q45) }\end{array}$ & $213(0.053) 5.3$ & $165(0.041) 4.1$ & $167(0.043) 4.3$ & $146(0.037) 3.7$ & $\begin{array}{c}124(0.031) \\
3.1 \\
\end{array}$ \\
\hline $\begin{array}{c}\text { Congenital malformations } \\
\text { of the genital organs (Q50-Q56) }\end{array}$ & $94(0.024) 2.4$ & $94(0.023) 2.3$ & $102(0.026) 2.6$ & $125(0.031) 3.1$ & $67(0.017) 1.7$ \\
\hline $\begin{array}{c}\text { Congenital malformations } \\
\text { of the urinary system (Q60-Q64) }\end{array}$ & $97(0.024) 2.4$ & $86(0.021) 2.1$ & $115(0.029) 2.9$ & $\begin{array}{c}120(0.030) \\
3.0\end{array}$ & $56(0.014) 1.4$ \\
\hline $\begin{array}{l}\text { Congenital malformations and } \\
\text { deformities of the musculoskeletal } \\
\text { system (Q65-Q79) }\end{array}$ & $245(0.061) 6.1$ & $212(0.053) 5.3$ & $234(0.060) 6.0$ & $197(0.049) 4.9$ & $172(0.043) 4.3$ \\
\hline $\begin{array}{l}\text { Other congenital malformations } \\
\text { (Q80-Q89) }\end{array}$ & $93(0.023) 2.3$ & $79(0.020) 2.0$ & $100(0.026) 2.6$ & $80(0.020) 2.0$ & $53(0.013) 1.3$ \\
\hline $\begin{array}{c}\text { Chromosomal abnormalities, } \\
\text { not elsewhere classified (Q90-Q99) }\end{array}$ & $90(0.023) 2.3$ & $58(0.014) 1.4$ & $60(0.015) 1.5$ & $41(0.010) 1.0$ & $49(0.012) 1.2$ \\
\hline
\end{tabular}

Note: $\mathrm{n}$ - number, $\mathrm{p}$ - prevalence per 10,000 births

Table 2. Cause specific death rate of congenital malformations in Kazakhstan per 100,000 live births (2015-2019).

\begin{tabular}{cccccc}
\hline Type of congenital malformation according to ICD 10 & \multicolumn{3}{c}{ Years } \\
\cline { 2 - 6 } & $\begin{array}{c}2015 \\
n\left(^{*}\right)\end{array}$ & $\begin{array}{c}2016 \\
n\left(^{*}\right)\end{array}$ & $\begin{array}{c}2017 \\
n\left(^{*}\right)\end{array}$ & $\begin{array}{c}2018 \\
n\left(^{*}\right)\end{array}$ & $\begin{array}{c}2019 \\
n\left(^{*}\right)\end{array}$ \\
\hline Congenital malformations of the nervous system (Q00-Q07) & $8(2.00)$ & $5(1.24)$ & $3(0.77)$ & $2(0.50)$ & $2(0.50)$ \\
\hline Congenital malformations of the circulatory system (Q20-Q28) & $41(10.26)$ & $27(6.71)$ & $17(4.34)$ & $18(4.52)$ & $16(3.99)$ \\
\hline Congenital malformations of the respiratory system (Q30-Q34) & $15(3.75)$ & $4(0.99)$ & $4(1.02)$ & $7(1.76)$ & $8(1.99)$ \\
\hline Cleft lip and palate [cleft lip and cleft palate] (Q35-Q37) & $0(0.00)$ & $0(0.00)$ & $0(0.00)$ & $0(0.00)$ & $0(0.00)$ \\
\hline Other congenital malformations of the digestive system (Q38-Q45) & $7(1.75)$ & $3(0.75)$ & $1(0.26)$ & $2(0.50)$ & $1(0.25)$ \\
\hline Congenital malformations of the urinary system (Q60-Q64) & $1(0.25)$ & $2(0.50)$ & $1(0.26)$ & $0(0.00)$ & $0(0.00)$ \\
\hline $\begin{array}{c}\text { Congenital malformations and deformities } \\
\text { of the musculoskeletal system (Q65-Q79) }\end{array}$ & $4(1.00)$ & $4(0.99)$ & $4(1.02)$ & $2(0.50)$ & $2(0.50)$ \\
\hline Other congenital malformations (Q80-Q89) & $16(4.00)$ & $14(3.48)$ & $5(1.28)$ & $9(2.26)$ & $4(1.00)$ \\
\hline Chromosomal abnormalities. not elsewhere classified (Q90-Q99) & $1(0.25)$ & $1(0.25)$ & $0(0.00)$ & $2(0.50)$ & $1(0.25)$ \\
\hline
\end{tabular}

Note: $\mathrm{n}$ - number of infants, died from this type of congenital malformation; ${ }^{*}$ CSDR - cause-specific death rate.

decreased in 2019, by 43\%, and amounted to 1.2 per 10,000 infants. In 2019, the prevalence of congenital malformations of the eye, ear, face and neck, in comparison with 2015, decreased by $13 \%$ (from 0.8 to 0.7 per 10,000 infants). However, the percentage change in the prevalence of congenital malformations of the respiratory system, during this period, showed an increase up to $14 \%$, from 0.7 to 0.8 per 10,000 infants.

We analysed the perinatal, neonatal and post-neonatal mortality rates based on the territorial distribution (Tables 4, 5, 6). During the studied period, the highest values of perinatal mortality were recorded 
Table 3. Percent change in the prevalence rate (\% change) of congenital malformations in the Kazakhstan for 2015-2019.

\begin{tabular}{cccc}
\hline Type of congenital malformation according to ICD 10 & 2015 & 2019 & $\%$ change \\
\hline Congenital malformations of the nervous system (Q00-Q07) & 2.5 & 1.5 & $-40 \%$ \\
\hline Congenital malformations of the eye, ear, face and neck (Q10-Q18) & 0.8 & 0.7 & $-13 \%$ \\
\hline Congenital malformations of the circulatory system (Q20-Q28) & 18.3 & 11.6 & $-37 \%$ \\
\hline Congenital malformations of the respiratory system (Q30-Q34) & 0.7 & 0.8 & $+14 \%$ \\
\hline Cleft lip and palate [cleft lip and cleft palate] (Q35-Q37) & 3.4 & 2.1 & $-38 \%$ \\
\hline Other congenital malformations of the digestive system (Q38-Q45) & 5.3 & 3.1 & $-42 \%$ \\
\hline Congenital malformations of genitals Q50-Q56) & 2.4 & 1.7 & $-29 \%$ \\
\hline Congenital malformations of the urinary system (Q60-Q64) & 2.4 & 1.4 & $-42 \%$ \\
\hline Congenital malformations of the musculoskeletal system (Q65-Q79) & 6.1 & 4.3 & $-30 \%$ \\
\hline Other congenital malformations (Q80-Q89) & 2.3 & 1.3 & $-43 \%$ \\
\hline Chromosomal abnormalities, not elsewhere classified & 2.3 & 1.2 & $-48 \%$ \\
\hline
\end{tabular}

Table 4. Perinatal mortality rate per 1,000 births (live birth and stillbirth) in Kazakhstan by region (2015-2019).

\begin{tabular}{|c|c|c|c|c|c|}
\hline \multirow[b]{2}{*}{ Region of Kazakhstan } & \multicolumn{5}{|c|}{ Years } \\
\hline & $\begin{array}{c}2015 \\
n\left(^{*}\right) \\
\end{array}$ & $\begin{array}{c}2016 \\
n\left(^{*}\right) \\
\end{array}$ & $\begin{array}{c}2017 \\
n\left({ }^{*}\right) \\
\end{array}$ & $\begin{array}{c}2018 \\
n\left({ }^{*}\right) \\
\end{array}$ & $\begin{array}{c}2019 \\
n\left({ }^{*}\right) \\
\end{array}$ \\
\hline Akmola region & $164(13.99)$ & $142(12.24)$ & $123(10.85)$ & $130(11.55)$ & $135(12.00)$ \\
\hline Aktobe region & 233(11.58) & $262(13.10)$ & $256(13.31)$ & 239(12.07) & $244(11.85)$ \\
\hline Almaty region & 492(11.98) & $514(12.29)$ & $496(12.33)$ & $541(13.21)$ & $629(15.32)$ \\
\hline Atyrau region & $225(13.63)$ & $220(13.12)$ & $200(12.15)$ & 209(12.31) & 235(13.96) \\
\hline West-Kazakhstan region & 155(11.86) & $169(12.71)$ & $166(12.77)$ & $152(11.50)$ & $167(12.63)$ \\
\hline Jambyl Region & 295(11.08) & $284(10.83)$ & $222(8.99)$ & $243(9.61)$ & $243(9.51)$ \\
\hline Karaganda region & 289(11.72) & $289(12.02)$ & $311(13.56)$ & 277(11.98) & $295(12.80)$ \\
\hline Kostanay region & $180(14.01)$ & $169(13.67)$ & $180(15.20)$ & $183(15.68)$ & $171(14.88)$ \\
\hline Kyzylorda Region & $279(14.35)$ & $244(12.90)$ & $226(12.05)$ & $210(11.14)$ & $234(12.38)$ \\
\hline Mangystau region & $284(14.71)$ & $281(14.07)$ & $237(12.10)$ & $262(13.00)$ & 294(14.29) \\
\hline South Kazakhstan region & $1257(15.70)$ & $1200(14.97)$ & $1140(14.75)$ & $1144(14.37)$ & 1086(13.14) \\
\hline Pavlodar region & $137(10.63)$ & $152(12.04)$ & $137(11.41)$ & $133(11.23)$ & $117(10.25)$ \\
\hline North-Kazakhstan region & $85(11.01)$ & $87(11.96)$ & $71(10.04)$ & $87(12.77)$ & $66(10.18)$ \\
\hline East Kazakhstan region & $312(13.75)$ & $310(13.63)$ & 285(12.96) & $247(11.40)$ & 251(11.64) \\
\hline Nur-Sultan city & 268(10.19) & $261(9.52)$ & $256(9.23)$ & $232(8.34)$ & $200(7.30)$ \\
\hline Almaty city & $372(8.79)$ & $422(9.53)$ & $378(8.51)$ & $414(9.13)$ & $378(8.29)$ \\
\hline Republic of Kazakhstan & $5124(12.71)$ & $5103(12.57)$ & $4756(12.03)$ & $4760(11.83)$ & 4805(11.86) \\
\hline
\end{tabular}

Note: $\mathrm{n}$ - number of fetal deaths 28 or more weeks gestation + the number of newborns dying under 7 days of age,

*-Perinatal Mortality Rate per 1,000 live births

in the South Kazakhstan region (Table 4). In 2015, 1257 (15.7) cases of perinatal mortality per 1,000 live births were recorded in South Kazakhstan. Despite the retained high rates in 2019, this indicator decreased to $\mathrm{n}=1086(13.14)$ per 1,000 live births.

High rates of perinatal mortality were identified in the Almaty region, as well. In 2019 (compared to 2015), there was an increase in perinatal mortality from 11.98 to 15.32 per 1,000 live births. Among all Kazakhstan large cities, in Almaty (2019 vs. 2015) there was an average level of perinatal mortality, with a slight difference from 8.79 to 8.29 per 1,000 live births. However, in the city of Nur-Sultan in 2019 there was a decrease in perinatal mortality, 7.3 per 1,000, compared to 2015 (10.19 per 1,000). In 2019, the perinatal mortality rates were almost equal in the Atyrau region and Mangystau region, 13.96 and 14.29 per 1,000 live births, respectively. Nevertheless, in 2015 these numbers were also high: 13.63 and 14.71 per 1,000 live births, respectively.

Data on neonatal mortality by regional distribution in Kazakhstan between 2015-2019 are presented in Table 5. The highest neonatal mortality, 6.5 per 1,000 in 2015, was observed in the South Kazakhstan 
Table 5. Neonatal mortality rate per 1,000 live births in Kazakhstan by region (2015-2019).

\begin{tabular}{|c|c|c|c|c|c|}
\hline \multirow[b]{2}{*}{ Region of Kazakhstan } & \multicolumn{5}{|c|}{ Years } \\
\hline & $\begin{array}{c}2015 \\
\mathrm{n}\left({ }^{*}\right)\end{array}$ & $\begin{array}{c}2016 \\
\mathrm{n}\left({ }^{*}\right)\end{array}$ & $\begin{array}{c}2017 \\
\mathbf{n}\left({ }^{*}\right)\end{array}$ & $\begin{array}{c}2018 \\
\mathbf{n}(*)\end{array}$ & $\begin{array}{c}2019 \\
\mathrm{n}\left({ }^{*}\right)\end{array}$ \\
\hline Akmola region & $51(4.40)$ & $40(3.48)$ & $36(3.21)$ & $36(3.23)$ & $51(4.58)$ \\
\hline Aktobe region & $122(6.11)$ & $106(5.35)$ & $88(4.62)$ & $100(5.10)$ & $116(5.68)$ \\
\hline Almaty region & $260(6.38)$ & $246(5.93)$ & $221(5.54)$ & $218(5.37)$ & $229(5.64)$ \\
\hline Atyrau region & $81(4.96)$ & $76(4.58)$ & $71(4.36)$ & $106(6.31)$ & $139(8.33)$ \\
\hline West-Kazakhstan region & $67(5.17)$ & $67(5.09)$ & $64(4.97)$ & $55(4.20)$ & $62(4.73)$ \\
\hline Jambyl Region & $168(6.35)$ & $129(4.96)$ & $97(3.95)$ & $81(3.23)$ & $120(4.73)$ \\
\hline Karaganda region & $124(5.07)$ & 119(4.99) & $99(4.36)$ & $109(4.76)$ & $125(5.48)$ \\
\hline Kostanay region & $88(6.91)$ & $65(5.32)$ & $84(7.17)$ & $74(6.42)$ & $72(6.34)$ \\
\hline Kyzylorda Region & $116(6.03)$ & $119(6.35)$ & $68(3.66)$ & $92(4.92)$ & $94(5.02)$ \\
\hline Mangystau region & $107(5.60)$ & $126(6.37)$ & $100(5.15)$ & $114(5.71)$ & $124(6.08)$ \\
\hline South Kazakhstan region & $514(6.50)$ & $465(5.87)$ & $391(5.12)$ & $332(4.22)$ & $353(4.32)$ \\
\hline Pavlodar region & $55(4.30)$ & $59(4.72)$ & $59(4.96)$ & $43(3.66)$ & $46(4.06)$ \\
\hline North-Kazakhstan region & 29(3.79) & $37(5.13)$ & $39(5.56)$ & $38(5.63)$ & $37(5.75)$ \\
\hline East Kazakhstan region & $137(6.10)$ & $127(5.64)$ & $100(4.59)$ & $107(4.98)$ & $110(5.14)$ \\
\hline Nur-Sultan city & $111(4.25)$ & $97(3.56)$ & $89(3.23)$ & $88(3.18)$ & $81(2.97)$ \\
\hline Almaty city & $226(5.37)$ & $192(4.36)$ & $189(4.28)$ & $199(4.42)$ & $176(3.89)$ \\
\hline Republican organizations & $98(16.86)$ & $87(13.64)$ & $85(12.89)$ & $70(8.81)$ & $69(9.32)$ \\
\hline Republic of Kazakhstan & $\begin{array}{c}2354 \\
(5.89)\end{array}$ & $\begin{array}{c}2157 \\
(5.36)\end{array}$ & $\begin{array}{c}1880 \\
(4.80)\end{array}$ & $\begin{array}{c}1872 \\
(4.70)\end{array}$ & $\begin{array}{l}2004 \\
(4.99)\end{array}$ \\
\hline
\end{tabular}

Note: $\mathrm{n}$ - number of deaths in the neonatal period (0-27 days), *-Perinatal Mortality Rate per 1000 live births

Table 6. Postneonatal mortality rate per 1,000 live births in Kazakhstan by region (2015-2019).

\begin{tabular}{cccccc}
\hline Region of Kazakhstan & \multicolumn{5}{c}{ Years } \\
\cline { 2 - 6 } & $\begin{array}{c}2015 \\
\mathrm{n}\left({ }^{*}\right)\end{array}$ & $\begin{array}{c}2016 \\
\mathrm{n}\left({ }^{*}\right)\end{array}$ & $\begin{array}{c}2017 \\
\mathrm{n}\left(^{*}\right)\end{array}$ & $\begin{array}{c}2018 \\
\mathrm{n}\left({ }^{*}\right)\end{array}$ & $\begin{array}{c}2019 \\
\mathrm{n}\left({ }^{*}\right)\end{array}$ \\
\hline Akmola region & $43(3.71)$ & $32(2.79)$ & $35(3.12)$ & $23(2.06)$ & $36(3.23)$ \\
\hline Aktobe region & $65(3.25)$ & $54(2.73)$ & $52(2.73)$ & $60(3.06)$ & $55(2.69)$ \\
\hline Almaty region & $129(3.17)$ & $139(3.35)$ & $131(3.29)$ & $115(2.84)$ & $151(3.72)$ \\
\hline Atyrau region & $43(2.63)$ & $59(3.56)$ & $39(2.39)$ & $70(4.16)$ & $50(3.00)$ \\
\hline West-Kazakhstan region & $40(3.09)$ & $33(2.51)$ & $21(1.63)$ & $30(2.29)$ & $24(1.83)$ \\
\hline Jambyl Region & $111(4.20)$ & $102(3.92)$ & $88(3.59)$ & $94(3.75)$ & $89(3.51)$ \\
\hline Karaganda region & $85(3.48)$ & $74(3.10)$ & $76(3.35)$ & $60(2.62)$ & $71(3.11)$ \\
\hline Kostanay region & $44(3.46)$ & $44(3.60)$ & $40(3.42)$ & $45(3.90)$ & $40(3.52)$ \\
\hline Kyzylorda Region & $82(4.26)$ & $61(3.25)$ & $83(4.47)$ & $69(3.69)$ & $78(4.17)$ \\
\hline Mangystau region & $74(3.87)$ & $63(3.18)$ & $44(2.27)$ & $60(3.00)$ & $68(3.34)$ \\
\hline South Kazakhstan region & $357(4.51)$ & $298(3.38)$ & $289(3.79)$ & $310(3.94)$ & $318(3.89)$ \\
\hline Pavlodar region & $29(2.27)$ & $42(3.36)$ & $29(2.44)$ & $29(2.47)$ & $33(2.91)$ \\
\hline North-Kazakhstan region & $30(3.92)$ & $14(1.94)$ & $23(3.28)$ & $34(5.04)$ & $22(3.42)$ \\
\hline East Kazakhstan region & $79(3.52)$ & $78(3.46)$ & $59(2.71)$ & $53(2.47)$ & $60(2.81)$ \\
\hline Nur-Sultan city & $82(3.14)$ & $78(2.87)$ & $65(2.36)$ & $69(2.50)$ & $70(2.57)$ \\
\hline Almaty city & $114(2.71)$ & $79(1.80)$ & $82(1.86)$ & $89(1.98)$ & $98(2.16)$ \\
\hline Republican organizations & $91(15.65)$ & $83(13.02)$ & $83(12.59)$ & $88(11.07)$ & $59(7.97)$ \\
\hline Not
\end{tabular}

Note: $\mathrm{n}$ - number of deaths in the postneonatal period (28 days-1 year), *-Postneonatal mortality rate per 1000 live births

region. Due to a gradual decrease, in 2019 the neonatal mortality rate in this region was 4.32 per 1,000 live births. However, these numbers remained high compared to other regions.
The neonatal mortality in 2015 was 6.38 per 1,000 live births in the Almaty region, whilst 5.37 per 1,000 live births in the city of Almaty. In 2019, neonatal mortality went down in Almaty region and 
Table 7. Infant mortality rate per 1,000 live births in Kazakhstan by region (2015-2019).

\begin{tabular}{cccccc}
\hline \multirow{2}{*}{ Region of Kazakhstan } & \multicolumn{5}{c}{ Years } \\
\cline { 2 - 5 } & $\begin{array}{c}2015 \\
n\left({ }^{*}\right)\end{array}$ & $\begin{array}{c}2016 \\
\left.n{ }^{*}\right)\end{array}$ & $\begin{array}{c}2017 \\
n\left({ }^{*}\right)\end{array}$ & $\begin{array}{c}2018 \\
n\left(^{*}\right)\end{array}$ & $\begin{array}{c}2019 \\
n(*)\end{array}$ \\
\hline Akmola region & $94(8.11)$ & $72(6.27)$ & $71(6.32)$ & $59(5.29)$ & $87(7.81)$ \\
\hline Aktobe region & $187(9.36)$ & $160(8.08)$ & $140(7.35)$ & $160(8.15)$ & $171(8.37)$ \\
\hline Almaty region & $389(9.55)$ & $385(9.29)$ & $352(8.83)$ & $333(8.21)$ & $380(9.36)$ \\
\hline Atyrau region & $124(7.60)$ & $135(8.14)$ & $110(6.75)$ & $176(10.47)$ & $189(11.33)$ \\
\hline West-Kazakhstan region & $107(8.26)$ & $100(7.59)$ & $85(6.60)$ & $85(6.49)$ & $86(6.56)$ \\
\hline Jambyl Region & $279(10.55)$ & $231(8.88)$ & $185(7.54)$ & $175(6.98)$ & $209(8.23)$ \\
\hline Karaganda region & $209(8.55)$ & $193(8.10)$ & $175(7.71)$ & $169(7.38)$ & $196(8.59)$ \\
\hline Kostanay region & $132(10.37)$ & $109(8.92)$ & $124(10.59)$ & $119(10.32)$ & $112(9.86)$ \\
\hline Kyzylorda Region & $198(10.29)$ & $180(9.60)$ & $151(8.13)$ & $161(8.61)$ & $172(9.19)$ \\
\hline Mangystau region & $181(9.48)$ & $189(9.55)$ & $144(7.41)$ & $174(8.71)$ & $192(9.42)$ \\
\hline South Kazakhstan region & $871(11.01)$ & $733(9.26)$ & $680(8.91)$ & $652(8.29)$ & $671(8.21)$ \\
\hline Pavlodar region & $84(6.57)$ & $101(8.07)$ & $88(7.39)$ & $72(6.13)$ & $79(6.98)$ \\
\hline North-Kazakhstan region & $59(7.71)$ & $51(7.07)$ & $62(8.83)$ & $72(10.67)$ & $59(9.16)$ \\
\hline East Kazakhstan region & $216(9.61)$ & $205(9.10)$ & $159(7.30)$ & $160(7.45)$ & $170(7.95)$ \\
\hline Nur-Sultan city & $193(7.39)$ & $175(6.43)$ & $154(5.59)$ & $157(5.68)$ & $151(5.54)$ \\
\hline Almaty city & $340(8.08)$ & $271(6.16)$ & $271(6.14)$ & $288(6.39)$ & $274(6.05)$ \\
\hline Republic of Kazakhstan & $3852(9.64)$ & $3460(8.60)$ & $3119(7.97)$ & $3170(7.95)$ & $3326(8.28)$ \\
\hline Non $)$
\end{tabular}

Note: $\mathrm{n}$ - infant death (newborns dying under one year of age) *-Infant Mortality Rate per 1000 live births

Almaty city to 5.64 per 1,000 and 3.89 per 1,000 live births, respectively.

In the Atyrau region in 2015 the neonatal mortality was 4.96 per 1,000 live births. Nonetheless, unlike other regions in 2019, there was an almost twofold increase, 8.33 per 1,000 live births. In the Mangystau region, despite a slight decrease in neonatal mortality rates in 2017, there was an increase in 2019: 6.08 per 1,000 live births.

In 2015, in the South Kazakhstan region (Table 6 ), the highest values of post-neonatal mortality were 4.51 per 1,000 live births. However, by 2019, in the South Kazakhstan region, a gradual increase in post-neonatal mortality cases was again recorded: 3.89 per 1,000 live births.

A high level of post-neonatal mortality in 2015 was recorded in the Almaty region (3.17 per 1,000 live births) and in 2019 it increased up to 3.72 per 1,000 live births. The post-neonatal mortality in the city of Almaty and Zhambyl region in 2019 was reduced to 2.16 and 3.51 per 1,000 live births compared to 2015 (Almaty city 2.71 per 1,000 live births) and Zhambyl region (4.2 per 1,000 live births).

Data on infant mortality rate are presented in Table 7. The analysis showed that the highest infant mortality during 2015-2019 was registered in the South Kazakhstan region. However, in comparison with 2015, there was a slight decrease in infant mortality from congenital malformations in 2019 from 11.01 to 8.21 per 1,000 live births, respectively. The infant mortality in Almaty in 2019 (compared to 2015) was reduced from 8.08 to 6.05 per 1,000 live births. At the same time, in the Almaty region during this period there was a drop from 9.55 to 9.36 per 1,000 live births.

In 2015, in Atyrau region, the infant mortality rate was 7.6 per 1,000 live births. The analysis indicated that in 2019 the mortality rate increased up to 11.33 per 1,000 live births. An increase of infant mortality rates in 2019 to 9.42 was recorded in the Mangystau region (in comparison with 2015).

\section{Discussion}

To the best of our knowledge, this study is the first national research of the epidemiology of congenital malformations in Kazakhstan for the period 2015-2019. The analysis of the prevalence of congenital malformations is difficult, due to the problems with data collecting in many countries ${ }^{15}$.

However, the estimation and analysis on national level, including the prevalence of congenital malformations, is vital for studying the patterns or trends over time. The development of prevention programmes and effective planning can help to improve the current children mortality ${ }^{16}$.

The results of the study indicate that the prevalence of various forms of congenital malformations decreased on average by $30-40 \%$ during the study period in 2019 (compared to 2015). Nonetheless, we 
observed an increase in the prevalence of congenital malformations of the respiratory system by 14\% (2019 vs. 2015).

The analysis showed that the most frequently detected congenital malformations were defects of the circulatory system, as well as congenital malformations of the skeletal system and digestive organs. The prevalence of congenital heart defects has increased significantly over time throughout the world. According to some reports, Asian region had the highest prevalence of these congenital malformations ${ }^{17}$. In the United States, for the period 2010-2014, the numbers of 12 main types of congenital heart defects were 0.62 for the interrupted aortic arch, 16.87 for clubfoot and 19.93 per 100000 live births. Despite the fact that the prevalence of major birth defects remained relatively stable for 15 years, there was an increase in the prevalence of gastroschisis and Down syndrome ${ }^{17}$.

In most cases, the aetiology of congenital malformations has been associated with mother's and the unfavourable financial situation of the parents ${ }^{18}$. Some reports highlighted racial predisposition as a risk factor of developing certain congenital malformations ${ }^{19}$. Apart from that, the negative impact of environmental factors also plays a significant role ${ }^{20}$.

The results of our analysis demonstrated a high prevalence of congenital malformations of the circulatory system, in contrast to other types of congenital malformations. Our findings are similar to previous studies conducted in other countries ${ }^{18,21}$, indicating a prevalence of 43.4 per 10,000 live births. Some reports have associated the prevalence and development of severe malformations of the circulatory system with the presence of obesity or diabetes in mothers $^{22}$.

The prevalence of congenital malformations of the nervous system in 2019 was reduced by $40 \%$. This might be associated with the correct preparation for the planned pregnancy in Kazakhstan, with the use of folic acid in the first trimester of gestation (according to the local clinical protocol for pregnancy management). It is well known that the administration of prophylactic doses of folic acid is effective in reducing the risk of neural tube defects ${ }^{23}$.

For the entire study period, the highest values of perinatal, postnatal, neonatal and infant mortality from congenital malformations were recorded in the South Kazakhstan region, and high rates were in the Almaty region.

The prevalence and mortality caused by congenital malformations in the southern regions of Kazakhstan can be associated with the financial situation of residents of these regions ${ }^{24}$, who predominantly live in rural areas ${ }^{25}$. According to previous studies conducted in Poland, comparing urban and rural areas, there was a significant prevalence of congenital malformation $s^{26}$. All these indicate that the lack of proper prenatal screening for the detection of congenital malformations may play a negative role in morbidity.

A low level of all mortality rates from congenital malformations was recorded in the North Kazakhstan region. At the same time, western regions (Atyrau and Mangystau) showed an increase in neonatal, perinatal and infant mortality, in contrast to other forms of congenital malformations (2019 vs. 2015). These findings can be explained by the difference in the ethnic composition of the southern and the western regions. In fact, Atyrau and Mangystau regions are mainly populated by representatives of the Kazakh nationality ${ }^{27}$. The representatives of European nationalities (Russians) mainly live in the northern region of Kazakhstan ${ }^{28}$.

Termination of pregnancy for foetal abnormality (TOPFA) has been widely discussed in the literature. In different countries, the possible maximum terms for termination of pregnancy for medical reasons have been determined, which can vary within no more than 24-26 weeks of gestation ${ }^{29}$. According to clinical protocols for diagnosis and treatment of Republic of Kazakhstan, the optimal period for termination of pregnancy for medical reasons, both on the part of foetus and mother, is a gestation period of up to 22 weeks $^{30}$. In fact, there are different opinions on the termination of pregnancy, even for medical reasons ${ }^{31}$.

Kazakhstan is a multi-ethnic country and more than 130 nationalities live on the territory of Kazakhstan ${ }^{32}$. According to previously published data on ethnic, religious and cultural characteristics, representatives of Kazakh nationality are often not inclined to do abortion (European women had an average of 2.3 abortions, Russified Kazaks 1.3, and Kazakhs 0.4$)^{33}$. These findings indicate that most of the followers of Islamic tradition predominantly live in the South Kazakhstan region $193.4 \%$ of the total population) and Almaty region ( $80.7 \%$ of the total population $)^{34}$. In this regard, the regional distribution may play a role in the high mortality rates related to congenital anomalies, despite the trend observed in 2019.

The State Programmes of the Ministry of Health of the Republic of Kazakhstan to reduce maternal and child mortality are:

- 2008-2010: the Program for reducing the maternal and child mortality in the Republic of Kazakhstan for 2008-2010.

- "Salamatty Kazakhstan" for 2011 - 2015.

- "Densaulyk" 2016-2020. 
- Since 1993, UNICEF has worked with the government of Kazakhstan to reduce infant and child mortality. UNICEF activities are aimed at supporting Kazakhstan's efforts to promote the sustainable realization of children's rights, with particular attention to the rights of the most vulnerable children and their families. Primary health care contributes to the prevention of deaths among infants and children. UNICEF plays a key role in supporting primary health care reforms and reducing infant mortality in the country.

- "Densaulyk" 2020-2025.

\section{Study limitations}

This study has some limitations. Because of its retrospective nature, the study did not analyse the risk factors for development of congenital malformations, such as extra-genital pathology, maternal age, etc. Future prospective studies will help to establish the prevalence and aetiology of congenital malformations using the basics of epidemiology.

\section{Conclusions}

The analysis showed a decrease in the prevalence of some forms of congenital malformations in Kazakhstan. However, despite the observed decrease in the prevalence in the southern regions of the country, there is still a high incidence of various forms of congenital malformations, in particular of the circulatory system. This indicates the necessity for effective preventive measures, including improvement of prenatal screening, in regions with a high prevalence of congenital malformations. These results can be used for the optimization and improvement of the state program, to reduce the prevalence of congenital malformations and perinatal mortality.

\section{Author Contributions:}

Conceptualization, A.S. and R.B.; methodology, G.B.; software, A.S; validation, K.Zh. and S.A.; formal analysis, I.F.; investigation, A.S.; resources, R.B; data curation, M.K. and I.F.; writing-original draft preparation, D.O. and Sh.T.; writing-review and editing, A.S, G.B., M.K.; visualization, S.A. and K.Zh.; supervision, R.B.; project administration, A.S. All the authors have read and agreed with the final version of the article.

\section{Compliance with Ethics Requirements:}

"The authors declare no conflict of interest regarding this article"

"The authors declare that all the procedures and experiments of this study respect the ethical standards in the Helsinki Declaration of 1975, as revised in 2008(5), as well as the national law. Informed consent was obtained from all the patients included in the study"

"No funding for this study"

\section{Acknowledgements:}

The authors express their gratitude for the administrative and technical support provided by the S.D. Asfendiyarov Kazakh National Medical University.

\section{References}

1. Irisa Z, Vi IA, Gissler M. Monitoring of congenital anomalies in Latvia. Cent Eur J Public Health 2014;22(3):147-152. https://doi: 10.21101/cejph.a3893

2. Corsello G, Giuffrè M. Congenital malformations. J Matern Fetal Neonatal Med 2012;25(1):25-29.

3. National Center for Health Statistics U.S. Department of Health and Human Services, Centers for Disease Control and Prevention. https://www.cdc.gov/nchs/products/databriefs/db355.htm.

4. EUROCAT European network of population-based registries for the epidemiological surveillance of congenital anomalies.: https://eu-rd-platform.jrc.ec.europa.eu/eurocat_en. .

5. Whitby EN, Paley MN, Smith MF, Springg A, Woodhouse N, Griffiths PD. Low field strength magnetic resonance imaging of the neonatal brain. Archives of Disease in Childhood (fetal and neonatal) 2003;88(3):203-208.

6. WHO. Congenital anomalies. https://www.who.int/ news-room/fact-sheets/detail/congenital-anomalies.

7. Dolk H. EUROCAT: 25 years of European surveillance of congenital anomalies. Archives of Disease in Childhood Fetal and Neonatal edition. 2005;90(5):F355-F358.

8. Statistical collection of the Ministry of Health of the Republic of Kazakhstan "Health of the population of the Republic of Kazakhstan and the activities of health organizations." http://www.rcrz.kz/index.php/ru/?option=com content\&view $=$ article\& $i d=973$.

9. Shrestha S, Shrestha A. Prevalence of congenital malformations among babies delivered at a tertiary care hospital. JNMA 2020;58(225):310-313.

10. Elghanmi A, Razine R, Jou M, Berrada R. Congenital malformations among newborns in Morocco: A retrospective study. Pediatric Reports 2020;12(1):7405.

11. Mashhadi Abdolahi H, Kargar Maher MH, Afsharnia F, Dastgiri S. Prevalence of congenital anomalies: a community-based study in the northwest of Iran. ISRN Pediatr 2014;2014:920940.

12. Thomas EG, Higgins C, Westgate M-N, Lin AE, Anderka M, Holmes LB. Malformations Surveillance: Comparison between Findings at Birth and Age 1 Year. Birth Defects Research 2018;110(2):142-147.

13. Official internet account of Agency for Strategic planning and reforms of the Republic of Kazakhstan Bureau of National statistics. https://bala.stat.gov.kz/

14. WHO. Manual for International Classification of Diseases and Health Related Problems, World Health Organization, Geneva, Switzerland,1992.

15. Kirby RS. The prevalence of selected major birth defects in the United States. Semin Perinatol 2017;41(6):338-344.

16. Parker SE, Mai CT, Canfield MA, et al. Updated national birth prevalence estimates for selected birth defects in the 


\section{Epidemiology of congenital malformations in Kazakhstan - SADYKOVA et al}

United States, 2004-2006. Birth Defects Res A Clin Mol Teratol v2010;88(12):1008-1016.

17. Mai CT, Isenburg JL, Canfield MA, et al. National population-based estimates for major birth defects, 2010-2014. Birth Defects Res 2019;111(18):1420-1435.

18. Kim MA, Yee NH, Choi JS, Choi JY, Seo K. Prevalence of birth defects in Korean livebirths, 2005-2006. J Korean Med Sci 2012;27(10):1233-1240.

19. Le MT, Shumate CJ, Hoyt AT, Wilkinson AV, Canfield MA. The prevalence of birth defects among non-Hispanic Asian/ Pacific Islanders and American Indians/Alaska Natives in Texas, 1999-2015. Birth Defects Res 2019;111(18):1380-1388.

20. Lamichhane DK, Leem J-H, Park M, et al. Increased prevalence of some birth defects in Korea, 2009-2010. BMC Pregnancy and Childbirth 2016;16:6.

21. Chen LJ, Chiou JY, Huang JY, Su PH, Chen JY. Birth defects in Taiwan: A 10-year nationwide population-based, cohort study. J Formos Med Assoc 2020;119(1 Pt 3):553-559.

22. Morris JK, Springett AL, Greenlees R, et al. Trends in congenital anomalies in Europe from 1980 to 2012. PloS One 2018; 13(4):e0194986.

23. Canfield MA, Collins JS, Botto LD, et al. Changes in the birth prevalence of selected birth defects after grain fortification with folic acid in the United States: findings from a multi-state population-based study. Birth Defects Res A Clin Mol Teratol 2005;73(10):679-689.

24. Addressing the Causes of Poverty in Kazakhstan. Borden Magazine 2017;1. https:// www.borgenmagazine.com/addressing-causes-of-poverty-in-kazakhstan/.

25. Zhumashov Y, Tomanova M. Demographic impact of Kazakhstan's countryside education. Procedia-Social and Behavioral Sciences 2014;143. https:// doi:10.1016/j.sbspro.2014.07.404
26. Genowska A, Zalewska M, Jamiołkowski J, et al. Inequalities in mortality of infants under one year of age according to foetal causes and maternal age in rural and urban areas in Poland, 2004-2013. Annals of Agricultural and Environmental Medicine: AAEM 2016;23(2):285-291.

27. Tolesh F. The population history of Kazakhstan. Paper presented at: European Population Conference. Session 43: Former demographic regimes, June 13-16, 2012, Stockholm, Sweden.

28. Kadyraliyeva A, Zholdubaeva A, Mukhanbet A, Omirbekova A, Saparova Y, Daribaeva R. Multiculturalism in Kazakhstan. Utopía y Praxis Latinoamericana 2019;24(1):208-217.

29. Kose S, Altunyurt S, Yildırım N, et al. Termination of pregnancy for fetal abnormalities: main arguments and a decision-tree model. Prenatal Diagnosis 2015;35(11):1128-1136.

30. Order of the Minister of Health of the Republic of Kazakhstan. On the approval of the rules for performing artificial termination of pregnancy. No. 626 of 30.10.2009. https://online.zakon.kz/Document/?doc $\mathrm{id}=35893665 \#$ pos $=4 ;-106$.

31. Hessini L. Islam and abortion: the diversity of discourses and practices. IDS Bulletin 2008;39(3):18-27.

32. Gassanov Z, Kaidarova D, Ismailov Z, et al. Study of prostate cancer prevalence in Kazakhstan. Archives of the Balkan Medical Union 2020;55:582-591.

33. Agadjanian V, Qian Z. Ethnocultural identity and induced abortion in Kazakstan. Stud Fam Plann 1997;28(4):317-29.

34. The Agency On Statistics Of The Republic Of Kazakhstan. Results of the 2009National population census of the Republic of Kazakhstan. Analytical Report.: https:// www.liportal.de/ fileadmin/user_upload/oeffentlich/ Kasachstan/40_gesellschaft/Kaz2009_Analytical_report.pdf. 